\title{
Interdisciplinary Team Project - International Solar Decathlon
}

\section{Dr. James G Sullivan, University of Florida}

James' professional work experience includes consulting and lecturing on green construction techniques. His construction management experience includes work for Clark Construction, Bethesda, Maryland, and Hines, Inc., Atlanta, Georgia. His research focus has been on utilizing sustainable techniques in the construction industry form a contractor perspective. He was awarded his Ph.D. in 2007 from the University of Florida. His dissertation focus was on decision models relating to building outcomes and first costs. James is currently the Charles R. Perry Assistant Professor at the M.E. Rinker, Sr. School of Building Construction, University of Florida, Gainesville. His course work includes construction techniques, high performance, and surveying. Dr. Sullivan served as a Co-PI for the UF Solar Decathlon house that competed in Madrid, Spain, in 2011, and is currently Co-PI for University of Florida and University of Nebraska Building Energy Efficient Homes for America Project. In addition he serves on state and national boards relating to construction job training and placement. 


\title{
Interdisciplinary Team Project - International Solar Decathlon
}

\begin{abstract}
This paper reviews the participation of university students from various colleges and schools from the University of Florida working towards delivering a United States Department of Energy Solar Decathlon competition home to Madrid, Spain, for the summer of 2010 Solar Decathlon Europe. The study presents the participation of students involved through traditional phases of design and construction. It also identifies and details the composition of students involved across the almost two-year progress noting which college or school the students resided in and how the composition of students evolved throughout the process. The paper also reviews the curriculum for which the project was integrated and how concepts from the house are used in curriculum lessons learned and suggestions for future competitions are given.
\end{abstract}

\section{Introduction}

The goal of this paper is to share the integrated nature of an international work service project on a university campus - specifically the 2010 International Solar Decathlon. It is also to reflect upon the different skill sets and various participation levels of students across the schematic, design development, and construction process. The Solar Decathlon Europe (SDE) Competition was developed in 2007 using the U.S. Department of Energy's Solar Decathlon, held biennially in Washington D.C. ii. Like its predecessor, SDE calls for the designs from twenty international teams, each of which may be comprised of students all from one university, or a team that incorporates several different universities. Each team typically works for two years from conception to completion. According to the official website for Solar Decathlon Europe, "the objective of the participating teams is to design and build houses that consume as few natural resources as possible and produce minimum waste products during their life cycle. Particular emphasis is put on reducing energy consumption and on obtaining all the necessary energy from the sun" iv.

The purposes of the competition are both educative and scientific, working together to both educate the general public and to develop new technologies and methods related to the sustainable environment ${ }^{\text {iv }}$. Collectively, these two ambitions promote collaboration, which may in turn lead to new technology making its way to the market, or existing products being repurposed in creative methods ${ }^{\text {iv }}$. The 2010 competition ultimately consisted of seventeen 
teams, from North America, Europe and Asia. Each team constructed a sustainable house with a footprint less than 800 square feet in Madrid Spain over the course of 10 days and competed in ten contests of varying subject matter ${ }^{\text {iii }}$.

- Architecture

- Engineering and Construction

- Solar Systems and Hot Water

- Energy Balance

- Comfort Conditions

- Appliances and Functionality

- Communication and Social Awareness

- Industrialization and Market Viability

- Innovation

- Sustainability

\section{Team RE:Focus: Colleges and Departments}

This paper focuses on Team RE:Focus. At the initial stage the student team coined "Team Re:Focus" to represent their entry. The contests required by the Solar Decathlon organization were varied in subject matter and mandatory deliverables. This led the University of Florida to take an approach that utilized integrated design and a multi-disciplinary organization structure. Integrated design incorporates all disciplines that would be involved in the project at some point into the decision-making structure from the beginning. This method requires significantly more planning and compromise in the beginning stages of design, but produces a more holistically integrated project at completion. Ten different disciplines across the university were tasked with working together to prepare the designs and systems necessary to compete:

- Architecture

- Building Construction

- Interior Design

- Landscape Architecture

- Sustainability

- Environmental Engineering

- Mechanical Engineering

- Business

- Public Relations

- Acoustics

To manage the deliverables and maintain structure, each discipline was tasked with completing the work for the section of the house that they specialized in, but with the addition that all other disciplines were on hand to work out the logistics of all designed features. The following paragraphs describe the typical subject matter and specializations of the disciplines involved.

College of Design, Construction, and Planning - Architecture 
The architecture program at the University of Florida focuses on preparing students to design both the creative and practical aspects of structures. Students must "be perceptive, skilled and inventive-capable of acting in a responsible manner in today's profession, while continuing to learn throughout their lives so as to realize a visionary profession for the future" ${ }^{v}$. Emphasis is put on social awareness and working to develop a better built environment. The architecture students were responsible for the exterior structure and footprint of the building. Several of the architectural details were also designed and constructed by these students.

\section{College of Design, Construction and Planning - Acoustics}

The Architectural Acoustics Research Program is housed as a specialty within the School of Architecture. The program employs modeling, measurement, prediction and evaluation tools that were developed by the school's research laboratory to "extend traditional architectural expertise into the multi-sensory realm where the design of the total experiential environment of buildings can occur" ix . The competition required acoustic studies once the house was constructed in Florida to ensure the appropriate measures were taken to reduce vibrations and enhance the user experience in the house. These studies were performed by a doctoral student in the Acoustics Program.

\section{College of Design, Construction, and Planning - Building Construction}

The M.E. Rinker, Sr. School of Building Construction (Rinker) focuses on educating students in the field of construction management by developing both technical and managerial skills. Rinker is the oldest school of construction in the United States, having been founded over 75 years ago ${ }^{x}$. The school has also recently begun focusing on sustainable construction and practices with the goal of reducing unnecessary destruction of the natural environment. The building construction program was tasked with developing and maintaining the project schedule as well as the physical construction of the project on site in Gainesville. Additionally, some students were on hand during the design and planning phases to assist with the logistics of constructing some of the house's features.

\section{College of Design, Construction and Planning - Interior Design}

The interior design program focuses on preparing students to become designers to meet the needs, functions and requirements of users when developing interior plans ${ }^{\mathrm{vi}}$. Focus is also placed on embracing sustainability, as well as incorporating owners as active participants in the design process. For the Solar Decathlon Europe project, the interiors students were tasked with developing a flexible interior environment, both in built-in fixtures and finishes, which appealed to a vast range of international visitors and met the function needs of the program and team. It was also important that the interior correspond and support the overall concept that was developed for the building's architecture.

College of Design, Construction, and Planning - Landscape Architecture

The Department of Landscape Architecture is housed with the Urban and Regional Planning Department to in the School of Landscape Architecture and Planning as the University of 
Florida. The program is the oldest in the state and the only one that is professionally accredited xii. Sustainability is one of the main focuses of the program, as is also resource and land use planning, tourism, landscape management and perception and landscape history ${ }^{\text {xii }}$. The landscape architecture students were tasked with both developing the appropriate path for the multitude of required tours as well as the vegetation incorporated into the deck and site designs.

College of Design, Construction, and Planning - Sustainability (Interdisciplinary)

The Sustainability program is the final department housed under the College of Design, Construction and Planning to be involved in the Solar Decathlon Europe competition. The program acknowledges the belief that sustainable design must be "development that meets the needs of the present without compromising the ability of future generations to meet their own needs" vii. Any alterations to the natural environment generate both immediate and long-term consequences and it is important to be mindful of these when working on any new structures. The department focuses on incorporating the Hannover Principles into their studies. This document focuses on the "transformation and growth in understanding of our interdependence with nature" and allows for adaptation as knowledge of the natural environment expands (About Sustainability 2011). The principles, which are listed below, are all significant points to be incorporated in the design and planning of a sustainable house ${ }^{i}$ :

1. Insist on rights of humanity and nature to co-exist.

2. Recognize interdependence

3. Respect relationships between spirit and matter

4. Accept responsibility for the consequences of design decisions

5. Create safe objects of long-term value

6. Eliminate the concept of waste

7. Rely on natural energy flows

8. Understand the limitations of design

9. Seek constant improvement by the sharing of knowledge

The sustainability students were tasked with completing the sustainability report, which accounted for every sustainable feature incorporated into the project.

Warrington College of Business Administration - Business

The Business Administration program is housed in the Warrington College of Business Administration. In addition to administration the program incorporates and emphasis in marketing and is ideal for students "who want to plan and execute the conception, pricing, promotion and distribution of products and to manage customer relations in ways that benefit organizations and their stakeholders" xi. Much of the curriculum focuses on marketing research and communications ${ }^{\mathrm{xi}}$. The market viability report was delegated to the business administration students, with the intent of detailing exactly how much the house cost to be made by the university, how much it would cost to mass produce, and what sector of the market would be ideal for the type of house being built. 
The Public Relations students joined the communications team from the College of Journalism. The goal of the department is to develop professionals who are "trained in persuasive communications, with a background in journalism and the ability to think strategically as part of a management team" ${ }^{\mathrm{xv}}$. The department produces graduates who are qualified to work in a large variety of industries. For the Solar Decathlon Team, the public relations students were tasked with developing and executing a communications plan, including the incorporation of social media and managing any new media interest in the project. They worked to incorporate the branding philosophy that had been developed by the communications team into their plan.

\section{College of Engineering - Environmental Engineering}

The Environmental Engineering Sciences Department is one of several engineering programs housed in the College of Engineering. The origin of the program dates back to the 1950s and works to produce professions "who identify and design solutions for environmental problems"

viii. A few of the problem areas that they work in include: provision of safe drinking water, treatment and disposal of wastes, maintenance of air quality and the control of pollution ${ }^{\text {viii }}$. The environmental engineering students worked in connection with the sustainability students to develop sustainable site solutions. For this project, a focus was placed on sustainable management of water.

\section{College of Engineering - Mechanical Engineering}

Mechanical Engineering works in conjunction with Aerospace Engineering to form the Mechanical and Aerospace Engineering department. This particular program is exceptionally researched based, combining both state-of-the-art basic and collaborative initiatives ${ }^{\text {xiii }}$. The two disciplines merged in 2002 to form one department ${ }^{\text {xiii. }}$. Mechanical Engineering is specifically "broad in scope, encompassing design and analysis of vehicles, robotics, machinery, thermal and fluid engineering and energy" xiv. For the task of the RE:Focus house, the MAE students focused their efforts of reinvention of current energy technologies, to adjust to ensure the most optimum results for the climate of Madrid.

\section{Student Representation}

Once the general teams had been assembled, the students began working on the design and deliverables required by the competition organization. This work occurred in three different stages: preliminary design and planning, development of competition documents and initial construction of the house. Students worked for the project in a variety of capacities, with the possibility of earning academic credit, being 


\section{Overall Student Participation}

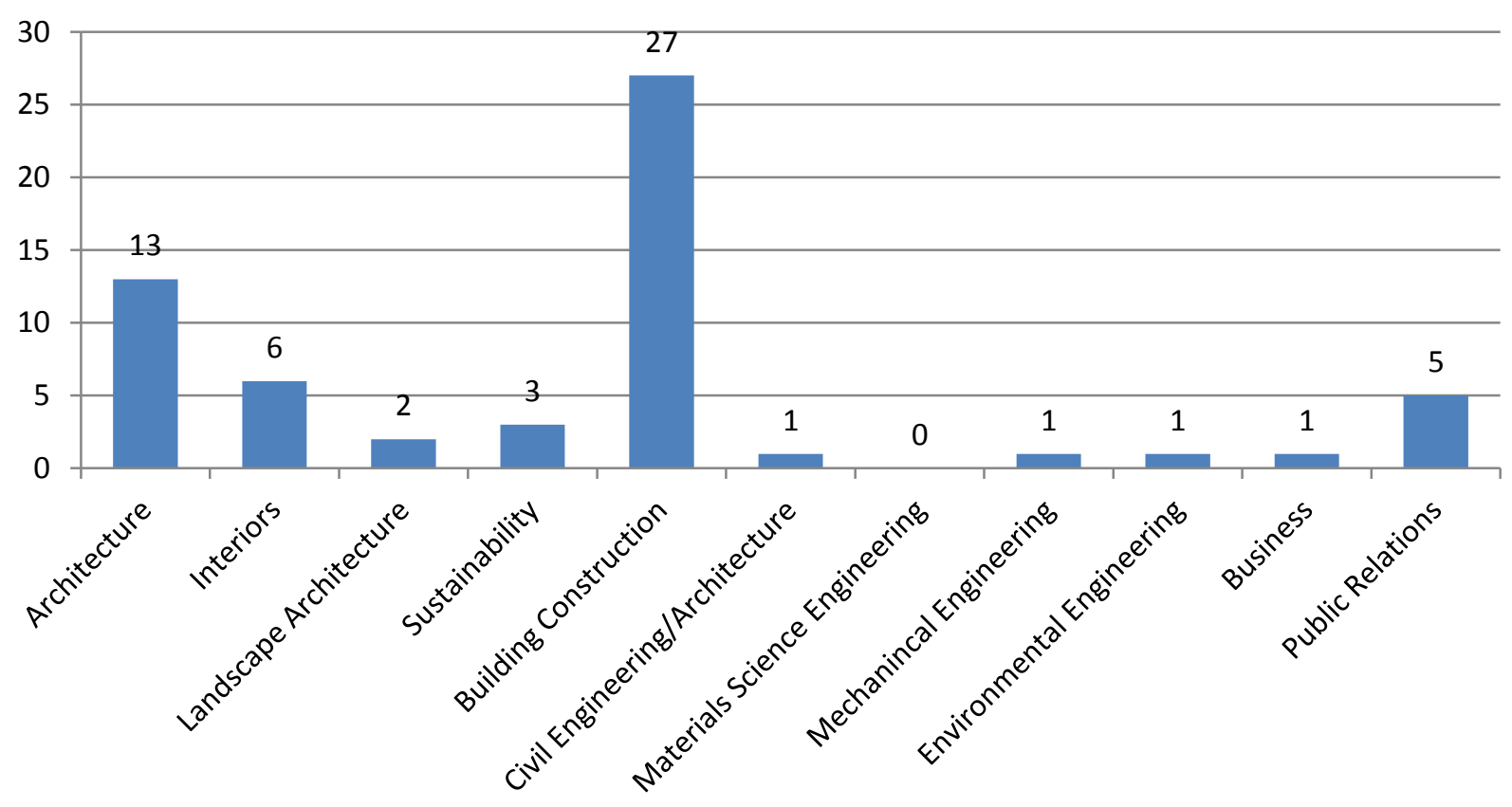

Figure 1: Overall Student Participation

employed for monetary compensation or volunteering. The following research is based on the accounts of students and faculty who participated in the competition and while they are complete to the knowledge of the author of this paper, some additional information may exist that was not uncovered during the research process. The distribution of students involved overall may be seen in Figure 1. This takes into all students that participated in the project both in the US and in Madrid.

Stage 1: Preliminary Design and Planning

Two charettes were used in the beginning of the design process to generate a multitude of concept and plan ideas. Several of the disciplines worked together on a volunteer basis for on the initial concepts, and following the second charette, the work was given to the architecture students to refine. The architecture students comprised the majority of the team at fifty-three 


\section{Stage 1: Preliminary Design \& Planning}

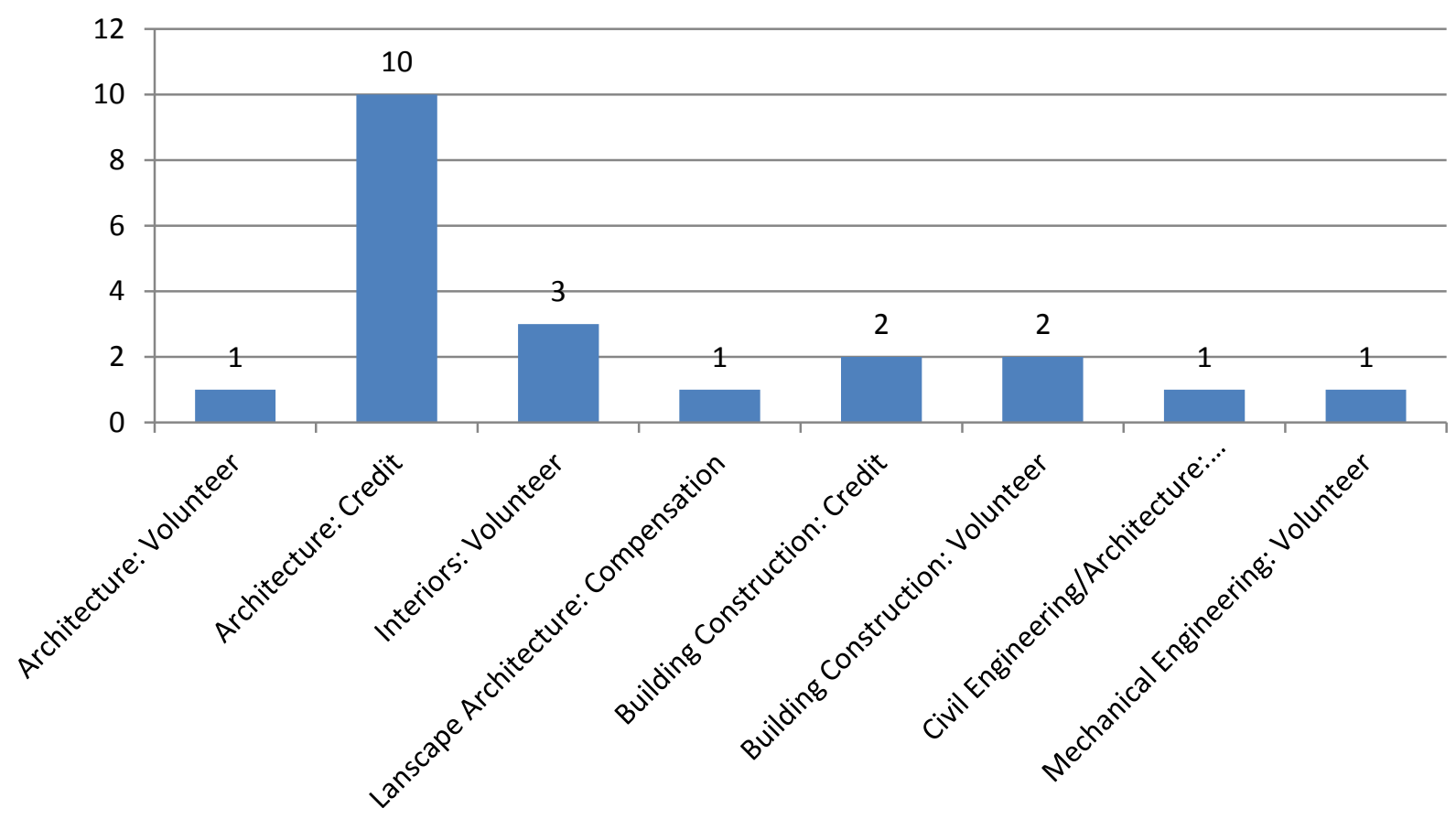

Figure 2: Preliminary Design

percent. During this stage, ten architecture students received academic credit (see Figure 2) to participate in a studio course devoted to the development of the Solar Decathlon house. They worked to finalize the house's concept, basic structure and initial materiality. Effort was also exerted to produce a brand for the house. The interior design students worked with the architecture students to ensure that the exterior envelope could accommodate the interior spatial needs. Building construction and engineering students offered insight into the scheduling of the project as well as the energy efficiency of the design, site orientation and implementation of technology to harvest renewable energy.

Stage 2: Development of Competition Documents

During the second stage of the design period, most ideas and concepts were refined and finalized, although as expected, some changes were necessary during the initial construction of the house. All disciplines participated in the preparation of the reports required by the competition organization and several additional work teams were formed to accomplish these tasks. Twenty-two percent of the students were involved in the architecture program, with building construction representing an additional twenty-two percent. The interiors and public relations students each accounted for an additional sixteen percent. The communications team was formed with students from architecture, interior design and public relations working together to brand the project, developing a social media presence, update sponsors and supporters via newsletters and blogs and develop a website. The market viability report was completed by architecture and interiors students, sustainability reports were written by sustainability students and construction drawings generated by architecture, interior design, building construction 
students and engineering students. During this time, all students of the University volunteered for the project, including those who had previously received academic credit (see Figure 3 ). The only exception to this is a

\section{Stage 2: Development of Competition Documents}

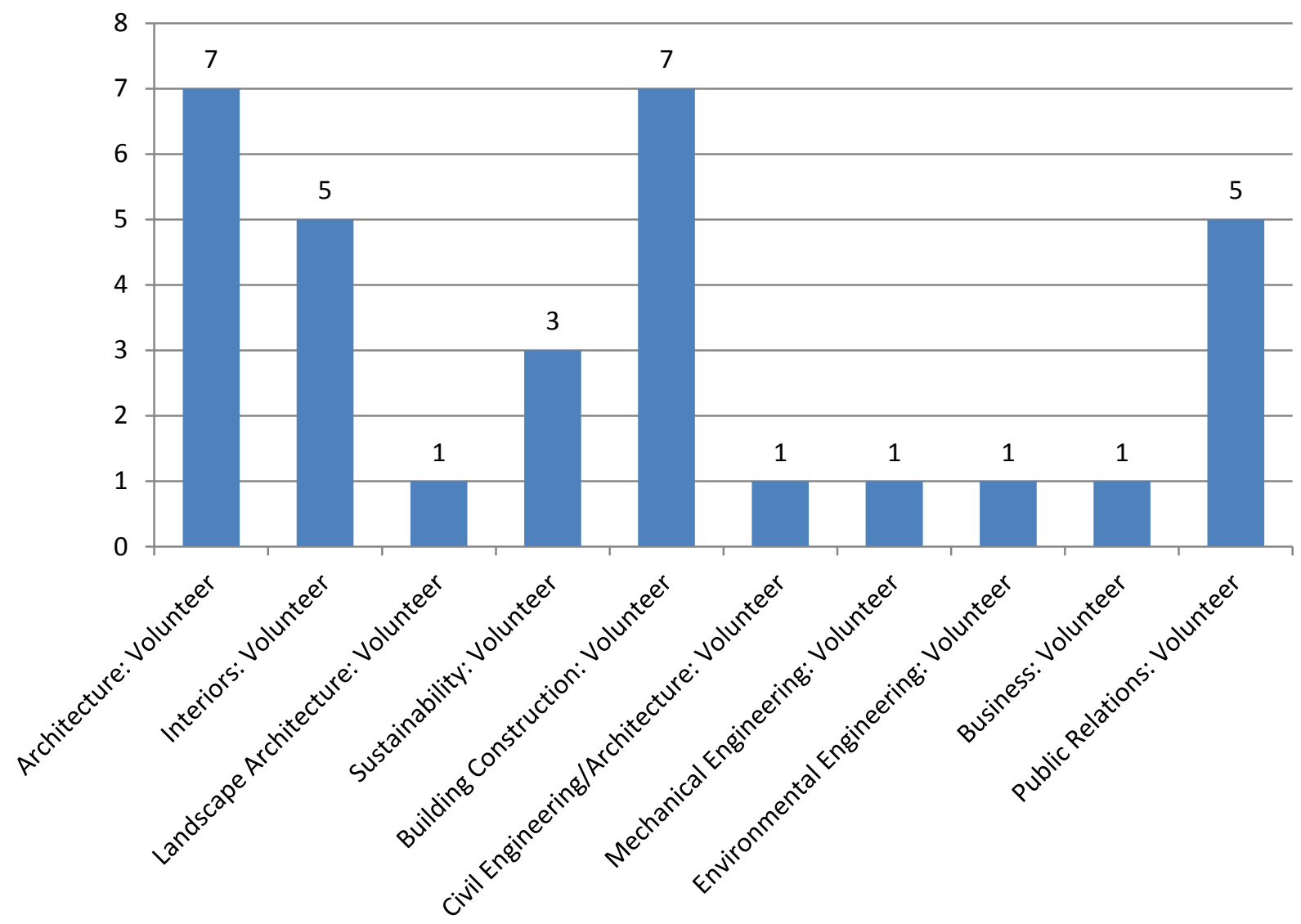

Figure 3: Development of Competition Documents

previous student who was hired to assist with construction documents and therefore received compensation. During this time, interdisciplinary design meetings were held bi-weekly, providing students with the opportunity to consult on logistical problems associated with any designs.

Stage 3: House Construction

Students worked for some six months exclusively on the construction of the house. During this time, all aspects of the design were finalized and ordered. The building construction student participation increased significantly, to sixty-six percent (Figure 4), 


\section{Stage 3: House Construction}

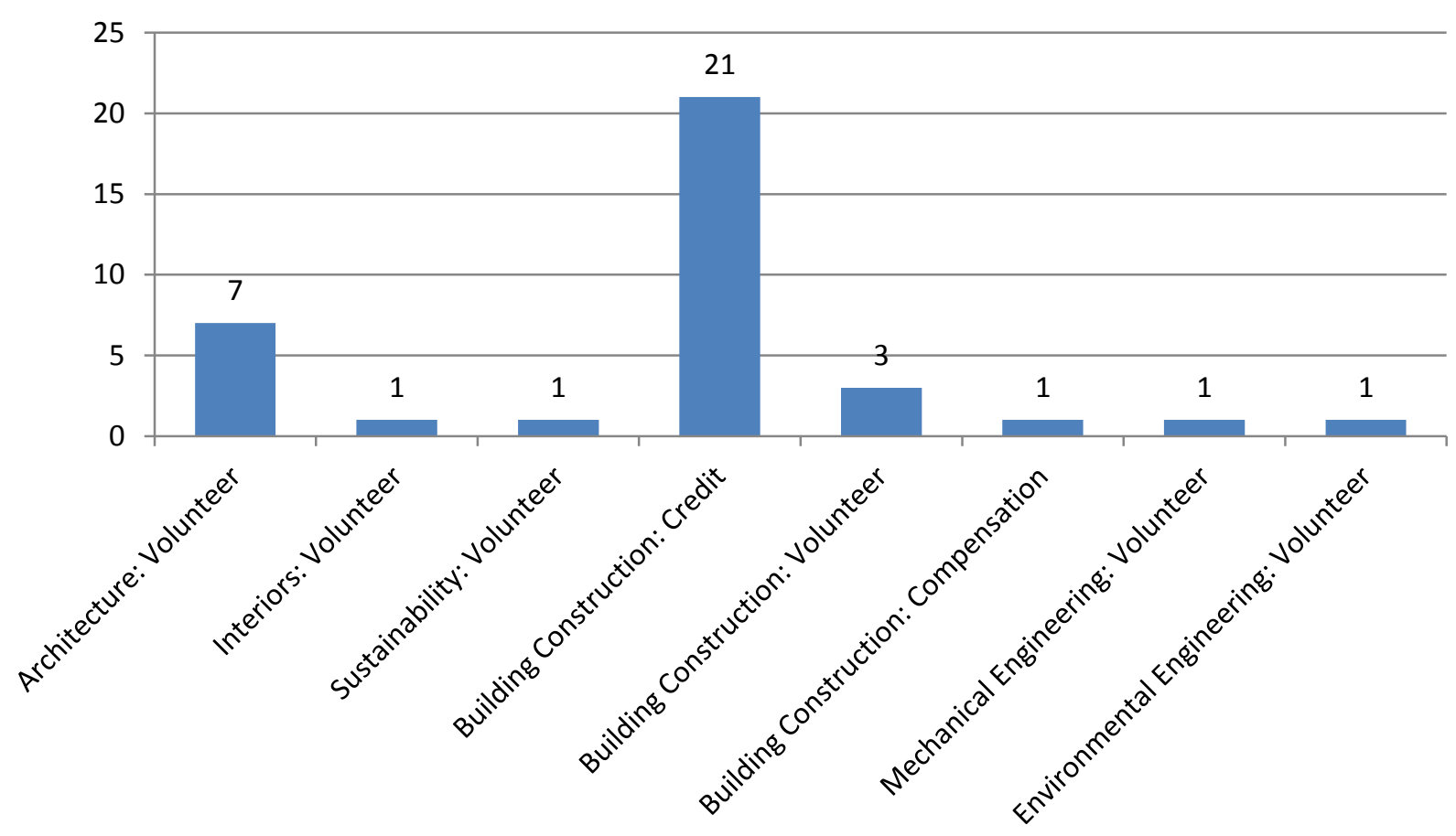

Figure 4: House Construction

due in part to the opportunity for them to earn academic credit. With the exception of building construction, all other students participated on a volunteer basis. Architecture, at nineteen percent, was the only other discipline with more than one student involved in the construction efforts. Once the majority of the house was constructed, careful deconstruction began. The components of the house were then packaged into shipping containers and sent to Madrid, Spain for the start of the competition.

\section{Work in Madrid Spain}

Once the designs had been finalized and the materials gathered, all components were shipped over to Europe in five shipping containers. The students went over in waves, with four main crews: pre-build, move and site construction, tour and competition and breakdown and repacking. Most students stayed for more than one crew, depending on their discipline and which aspect of the project they had been responsible for. Figure 5 shows the distribution of 
disciplines that went to Spain.

\section{Work in Spain}

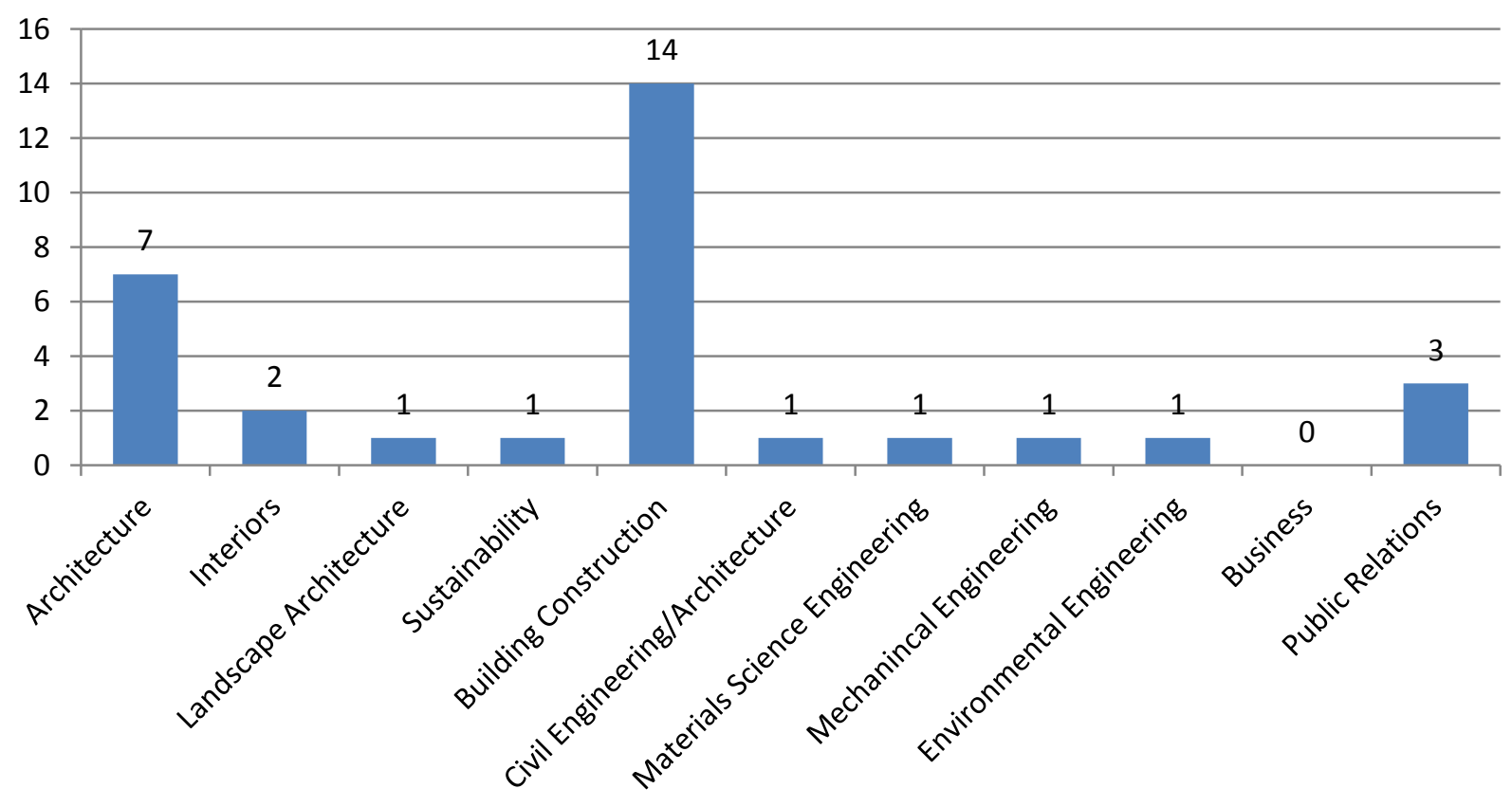

Figure 5: Work in Spain

Work in Spain differs from previous work in that the students were given both a stipend to compensate for the physical labor as well as a per diem to cover travel and living expenses. The building construction students make up almost half of the overall crew, at forty-four percent, while the architecture department is the second largest, at twenty-two percent. Interiors and public relations had six and ten percent respectively, while each other department sent one student representative. Each student is documented as having been compensated, rather than volunteering. The term compensated for this time period refers to any travel, housing, dining or expenses that were covered for the students. All monetary equivalents were dependent upon the duration of the individuals stay as well as their involvement in the team's leadership.

\section{Results and Post-Competition Work}

The University of Florida Team RE:Focus House placed eighth overall in the final results of the 2010 Solar Decathlon Europe Competition. The project won the communications category and placed second in the contest for energy balance for the duration of the competition. The team was also successful in obtaining the People's Choice Award, via the web. These results were considered overall successful and the project proved to be a phenomenal exercise in interdisciplinary design work. It accomplished the larger goal of bringing the University as a whole together, with several other individuals and departments promoting the project for the People's Choice Award.

During the course of designing the house, several options were proposed for the house's life after competition. Some suggestions (both serious and not) included a traveling exhibit, permanent 
exhibit at a campus museum, office space and time-shared condo. To date, the house is still located in its containers on university property, however a permanent home has been decided upon and monies are being identified to put towards its reconstruction.

This paper has attempted to present a clear and unbiased picture of the work completed for the Solar Decathlon project. To accomplish this, students have been represented solely by the discipline they were most integrated with during the work. Several students actually represented multiple departments and worked within both subject areas. Lastly, this project proved exceedingly difficult to quantify in terms of man-hours by students, therefore hour numbers were omitted. It should be noted, however, that there was no correlation between students who received academic credit or compensation and the amount of total hours worked. Academic credit was not given to all who devoted countless hours to the project and in some cases, hours given far exceeded the hours need to meet their obligations.

\section{Conclusions}

The project at the end was a tremendous success. The knowledge learned and shared by faculty, students, administrators, and supporting and contributing professionals will long outlast the physical design and construction of this project. Main lessons learned focus on student credit, finance, and time management - really not different from a non-scholastic design and construction project. From a coordination and student perspective it takes a flexible academic setting for which students receive scholastic credit for their efforts. Some programs had flexibility for this type of independent study and others did not - it is crucial for their academic balance to receive credit for effort. Solid systematic funding and understanding of budgeting and expenses is also crucial on a very unique project. It was difficult in the schematic and design development to develop accurate budget constraints due to the inter-related shipping, preconstruction, construction, and deconstruction factors that were also dependent on the design. This project was the first of its kind shipping materials from the US to another country - given other countries had competed in the US Solar Decathlon. Lastly time management of all involved across often independent and volunteer student and faculty was difficult. All the great intentions and allowing for free flow of ideas is great in theory but the practicality of meeting the competition deadlines as well as the students and faculty day to day responsibilities was at times difficult.

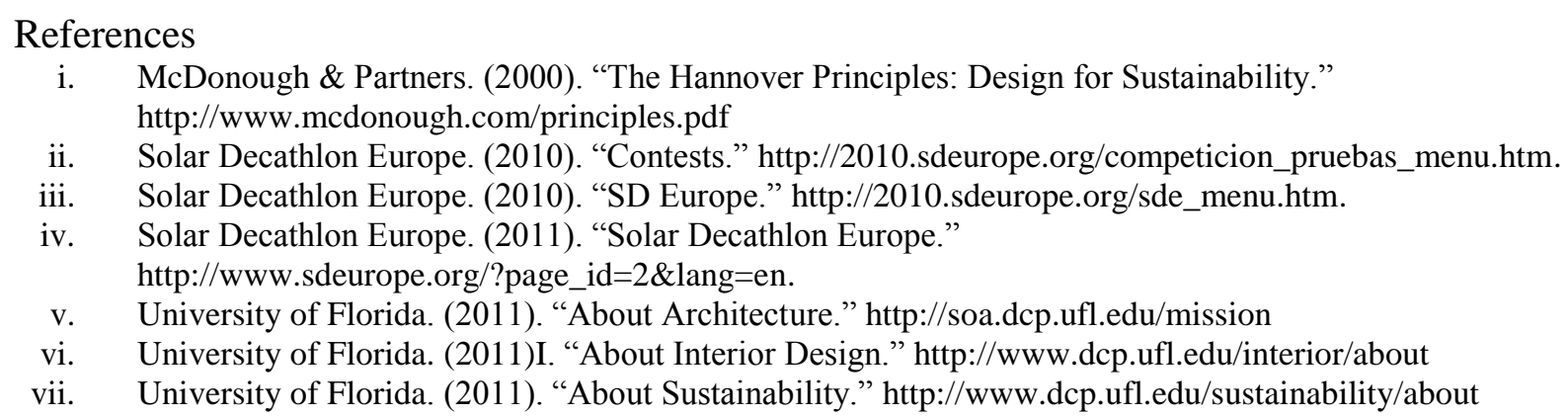


viii. University of Florida. (2011). "About the Department of Environmental Engineering." http://www.ees.ufl.edu/information/about.asp

ix. $\quad$ University of Florida. (2011). "Architectural Acoustics Research." http://gsoa.dcp.ufl.edu/main/categories/architecturalacousticsresearch

x. $\quad$ University of Florida. (2011). "BCN Director's Message." http://www.bcn.ufl.edu/dcp_director_message.shtml

xi. $\quad$ University of Florida. (2011). "Business Administration Overview." http://warrington.ufl.edu/sb/programs/mar.asp

xii. $\quad$ University of Florida. (2011). "Landscape Architecture Overview." http://www.dcp.ufl.edu/landscape/about/overview

xiii. $\quad$ University of Florida. (2011). "MAE Mission and Vision." http://www.mae.ufl.edu/newwebpage/AboutMAE/AboutMAE.aspx

xiv. $\quad$ University of Florida. (2011). "MAE Research Summary." http://www.mae.ufl.edu/newwebpage/AboutMAE/AboutMAE.aspx

xv. University of Florida. (2011). "Public Relations Introduction." http://www.jou.ufl.edu/academic/pr/default.asp 